\title{
Detection of Metastasis in a Patient-derived Orthotopic Xenograft (PDOX) Model of Undifferentiated Pleomorphic Sarcoma with Red Fluorescent Protein
}

\author{
HIROMICHI OSHIRO ${ }^{1,2,3^{*}}$, TASUKU KIYUNA ${ }^{1,2,3^{*}}$, YASUNORI TOME ${ }^{3}$, KENTARO MIYAKE $^{1,2}$, \\ KEI KAWAGUCHI ${ }^{1,2}$, TAKASHI HIGUCHI ${ }^{1,2}$, MASUYO MIYAKE $^{1,2}$, ZHIYING ZHANG $^{1,2}$, \\ SAHAR RAZMJOOEI ${ }^{1}$, MARYAM BARANGI ${ }^{1}$, SINTAWAT WANGSIRICHAROEN $^{1}$, SCOTT D. NELSON $^{4}$, \\ YUNFENG LI ${ }^{4}$, MICHAEL BOUVET ${ }^{2}$, SHREE RAM SINGH ${ }^{5}$, FUMINORI KANAYA $^{3}$ and ROBERT M. HOFFMAN ${ }^{1,2}$ \\ ${ }^{1}$ AntiCancer Inc., San Diego, CA, U.S.A.; \\ ${ }^{2}$ Department of Surgery, University of California, San Diego, CA, U.S.A.; \\ ${ }^{3}$ Department of Orthopedic Surgery, Graduate School of Medicine, University of the Ryukyus, Okinawa, Japan; \\ ${ }^{4}$ Department of Pathology, University of California, Los Angeles, CA, U.S.A.; \\ ${ }^{5}$ Basic Research Laboratory, National Cancer Institute, Frederick, MD, U.S.A.
}

\begin{abstract}
Background/Aim: Undifferentiated pleomorphic sarcoma (UPS) is a common soft tissue sarcoma and highly recalcitrant. We have previously developed patient-derived orthotopic xenograft (PDOX) mouse models of UPS and other major sarcoma types. Unlike PDOX models of other cancer types, it has been difficult to demonstrate metastasis in the sarcoma PDOX models. Materials and Methods: To visualize metastasis at high resolution in the UPS PDOX model, established tumor fragments were implanted in transgenic nude mice expressing red fluorescent protein (RFP) for one passage. The tumors acquired RFP-expressing stroma from transgenic host. UPS tumor with RFP stromal cells were harvested and implanted orthotopically in non-transgenic nude mice. After six weeks of UPS tumor growth in the PDOX
\end{abstract}

This article is freely accessible online.

*These Authors contributed equally to this study.

Correspondence to: Robert M. Hoffman, AntiCancer, Inc., 7917 Ostrow St., San Diego, CA 92111, U.S.A. E-mail: all@anticancer.com; Yasunori Tome, MD, Ph.D., Department of Orthopedic Surgery, Graduate School of Medicine, University of the Ryukyus, Okinawa, Japan. E-mail: yash_toume@hotmail.com; Shree Ram Singh, Basic Research Laboratory, National Cancer Institute, Frederick, MD, 21702, U.S.A. E-mail: singhshr@mail.nih.gov; Michael Bouvet, MD, Department of Surgery, University of California, San Diego, CA, U.S.A.E-mail: mbouvet@ucsd.edu

Key Words: Undifferentiated pleomorphic sarcoma, soft-tissue, patient-derived orthotopic xenograft, PDOX, red fluorescent protein, metastasis, stromal cell. model, the primary tumor was imaged non-invasively and lung, liver, and spleen were resected and imaged ex-vivo in order to visualize the presence of RFP, with a FluorVivo ${ }^{\circledR}$ imaging system and $F V 1000^{\circledR}$ confocal laser microscope, respectively. Results: The primary tumor was imaged noninvasively. Confocal microscopy visualized the presence of RFP in the lung and liver indicating metastases in these organs. This is the first report of metastasis in a sarcoma PDOX model. Conclusion: This study should prove very useful to screen for anti-metastatic drugs for the PDOX donor patients and to understand the metastatic process in sarcoma.

Undifferentiated pleomorphic soft-tissue sarcoma (UPS) is a common soft tissue sarcoma and is highly recalcitrant with a metastatic rate of $31-35 \%$. The common metastatic sites are lung $(90 \%)$, bone $(8 \%)$, and liver $(1 \%)(1,2)$. UPS patients are treated with surgical resection and radiotherapy. Because UPS is resistant to chemotherapy, standard chemotherapy protocols have not been developed. Therefore, development of effective therapy for UPS patients is needed.

Traditional imaging procedures such as optical imaging, intravital videomicroscopy, histopathological examination or immunohistochemistry (3-5) are either not sensitive or lacking spatial resolution to image early stage tumor growth or metastasis in mouse models of patient tumors. Therefore, developing stable, sensitive, non-invasive and ex-vivo methods are required to visualize early stages of tumor growth or metastasis.

In order to study metastasis of patient tumors in a mouse model, a patient-derived orthotopic xenograft (PDOX) nude mouse model was developed for all major cancers by our laboratory (6-17). The use of fluorescent proteins for in vivo 
imaging was also established by our laboratory $(18,19)$. We previously developed an imaginable PDOX model for pancreatic cancer, gastric leiomyosarcoma and undifferentiated pleomorphic soft-tissue sarcoma by passage of the PDOX tumor in transgenic red-fluorescent protein (RFP)-expressing nude mice, whereby the PDOX tumor stably acquired RFPexpressing stroma $(16,20,21)$.

In the present report, using this method for labeling the UPS tumor, we demonstrate for the first-time that metastasis can be visualized in a sarcoma PDOX model.

\section{Materials and Methods}

Mice. Athymic $n u / n u$ nude mice and transgenic RFP-expressing athymic nu/nu mice (22) (AntiCancer Inc., San Diego, CA, USA), 4-6 weeks old, were used in this study. All animal studies were conducted with an AntiCancer Institutional Animal Care and Use Committee (IACUC) protocol specifically approved for this study and in accordance with the principles and procedures outlined in the National Institute of Health Guide for the Care and Use of Animals under Assurance Number A3873-1. Mouse housing, feeding, surgical processes and imaging were conducted as previously described (23-29). The mice were humanely sacrificed as previously described (22-26).

Patient-derived tumor. The patient was diagnosed with UPS of the left thigh and had the tumor resected. The disease recurred locally a few months later and the patient was treated with radiotherapy, and subsequent re-resection at the Division of Surgical Oncology, University of California, Los Angeles (UCLA). Written informed consent was obtained from the patient as part of a UCLA Institutional Review Board (IRB \#10-001857)-approved protocol. We previously reported the establishment of a PDOX model of this UPS $(16,21,22-26)$.

Establishment of a fluorescent UPS PDOX model by surgical orthotopic implantation (SOI) in transgenic RFP-expressing nude mice. UPS tumors growing in nude mice were harvested, cut into 5 -mm fragments and then implanted subcutaneously in transgenic RFP-expressing nude mice. After the UPS tumor grew subcutaneously in transgenic RFP-expressing nude mice, the tumors were harvested and cut into small fragments and transplanted orthotopically in non-transgenic nude mice as follows: a 5-mm skin incision was made on the right high thigh into the biceps femoris, which was split to make space for the UPS tissue fragment. A single tumor fragment was implanted orthotopically into the space to establish the PDOX model in the non-transgenic nude mice (16). The wound was closed with a 6-0 nylon suture (Ethilon, Ethicon, Inc., NJ, USA). In the present study, 5 UPS PDOX models were established (Figure 1A).

Visualization of metastasis in the fluorescent UPS PDOX model. Six weeks after the UPS tumor was implanted orthotopically in nontransgenic nude mice, the tumor, lung, liver and spleen were resected. Fresh tissues were first cut thin with scissors and placed on slides to confirm the presence of RFP under a fluorescence microscope.

The tissues described above were embedded using optimal cutting temperature (OTC) compound (Tissue-Tek; Sakura Finetek Europe $\mathrm{BV}$, Zoeterwude, the Netherlands) in order to make frozen sections
Table I. Metastases in the UPS PDOX model.

\begin{tabular}{lccc}
\hline Mouse & Tumor & Lung & Liver \\
\hline 1 & + & + & + \\
2 & + & + & - \\
3 & + & - & + \\
4 & + & - & - \\
5 & - & - & - \\
\hline
\end{tabular}

and preserved in liquid nitrogen. The frozen tissue was sectioned at $7 \mu \mathrm{m}$ with a Cryomicrotome (Leica CM1850, Wetzler, Germany).

Imaging. The FluorVivo ${ }^{\circledR}$ (INDEC Bio System) and FV1000 ${ }^{\circledR}$ (Olympus) confocal laser microscope were used to observe RFP. The FluorVivo ${ }^{\circledR}$ was used to non-invasively image the primary tumor. Frozen tissue sections were observed with the FV1000 ${ }^{\circledR}$ confocal laser microscope. RFP was excited by a laser emitting at $559 \mathrm{~nm}$. A $4 \times$ objective lens and $20 \times$ objective lens were used in this experiment.

\section{Results and Discussion}

Six weeks after the UPS tumor with RFP stromal cells was implanted orthotopically in non-transgenic nude mice, the primary tumor was non-invasively imaged (Figure 1B). Then the primary tumor, lung, liver and spleen were resected.

Confocal microscopy demonstrated the presence of RFP in the lung and liver in one mouse, in another mouse in the lung and in another mouse in the liver, indicating the metastasis in these organs (Figure 2, Table I).

We were the first to report that stromal cells were necessary for metastasis (27). We subsequently reported that stromal cells from the primary tumor traveled to the metastasis site in a PDOX model of pancreatic cancer (20). Recently, our results that stromal cells are essential for cancer cell homing and colonization to other organs have been confirmed (28-30).

We have also shown that RFP host stromal cells from the primary tumor were observed in the metastasis to the lung in an orthotopic model of human osteosarcoma cell line (31).

The present study is the first to observe metastasis in a sarcoma PDOX model. Being able to visualize metastasis in a sarcoma PDOX model will be of value to screen for drugs to prevent or eradicate metastasis, which should be helpful to the donor patient. The metastatic sarcoma PDOX model will also be valuable to fully understand this disease throughout its entire course.

\section{Conflicts of Interest}

The Authors declare that there are no potential conflicts of interest in regard to this study. AntiCancer Inc. uses PDOX models for contract research. HO, TK, YT, KM, KK, TH, MM, ZZ, SR, MBa, SW and RMH are or were unsalaried associates of Anticancer Inc. 


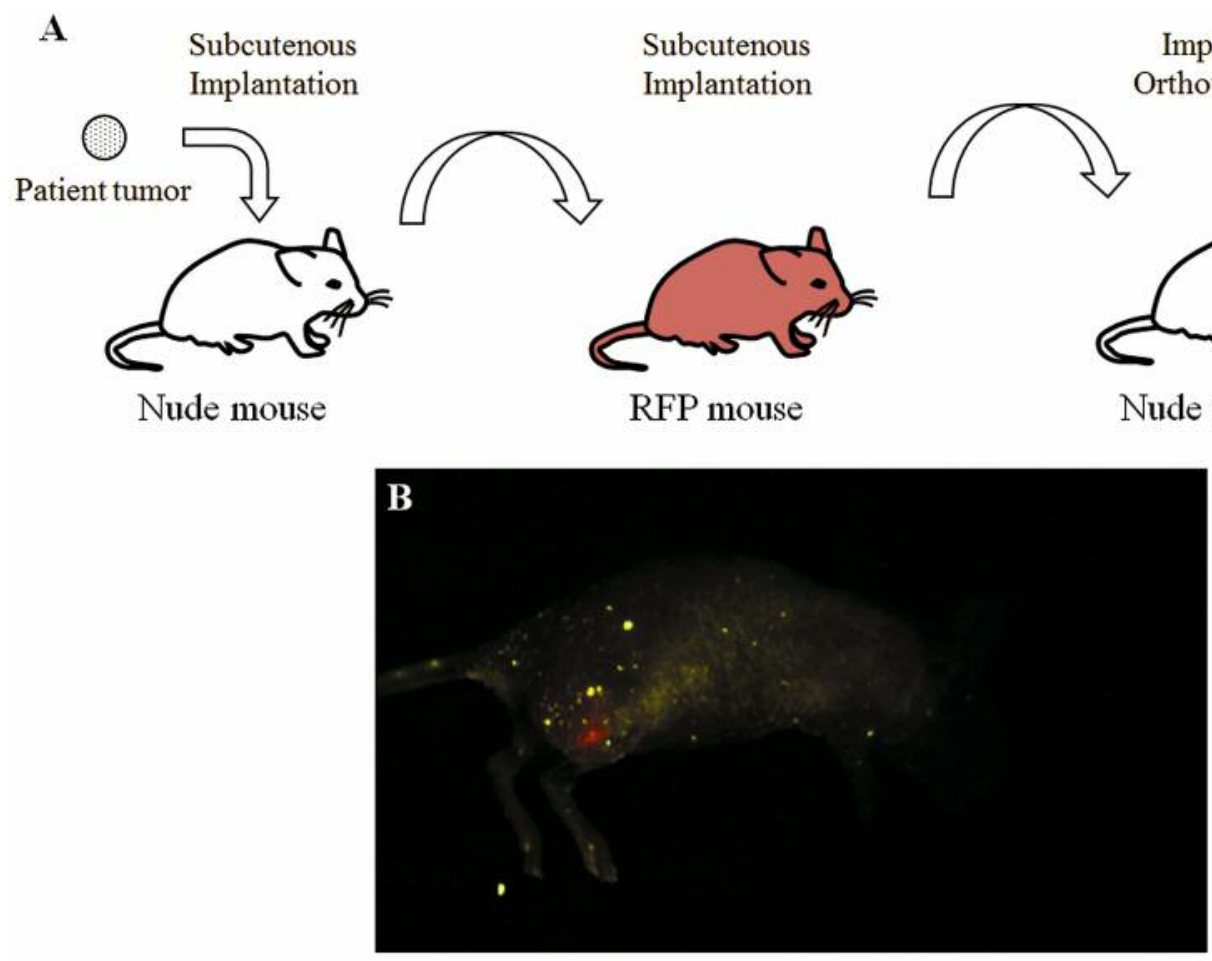

Fugure 1. Non-invasive imaging of a fluorescent tumor derived from a primary tumor of a patient with undifferentiated pleomorphic sarcoma, growing orthotopically in nude mice. (A) Experimenl schema for developing the imageable metastatic undiffrentiated pleomorphic sarcoma (UPS) PDOX model. The patient tumor was initially implanted in the subcutis of a non-transgenic nude mouse. After tumor growth, the tumor was then implanted in the subcutis of an RFP transgenic nude mouse. After tumor growth in RFP transgenic mice, tumor were finally implanted in an orthotopic site in the biceps femoris of non-transgenic nude mice. (B) Non-invasive imaging of the UPS PDOX primary tumor. The mouse was placed in the left lateral decubitus position. RFP expression of the primary tumor can be non-invasively visualized in the right high thigh.
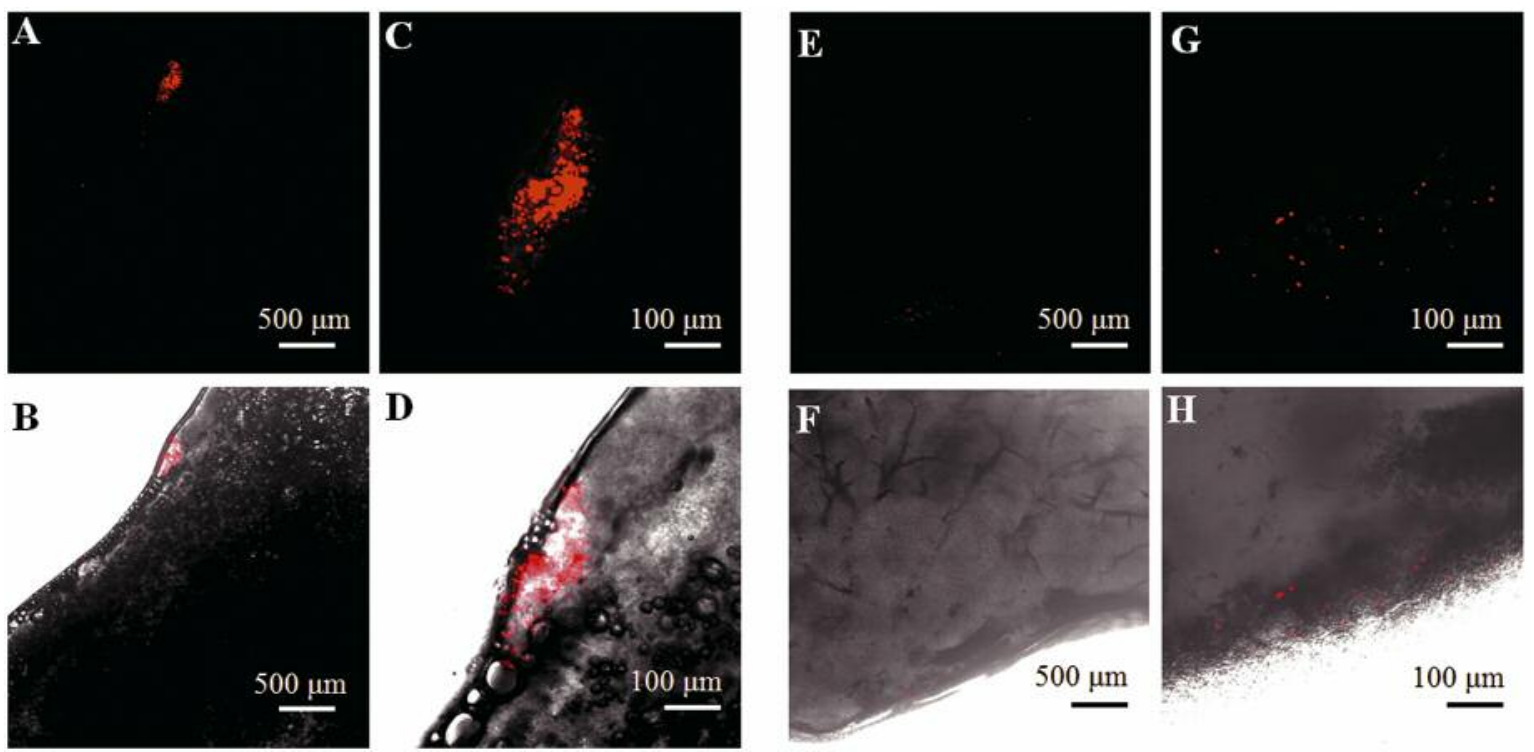

Figure 2. FV1000 ${ }^{\circledR}$ confocal laser microscopy of metastases in frozen sections. (A-D) Lung, $($ E-H) liver. (A, E) RFP expression at low magnification (Bar: $500 \mu \mathrm{m}) .(B, F)$ Merge at low magnification (Bar: $500 \mu \mathrm{m})$. (C, G) RFP expression at high magnification $($ Bar: $100 \mu \mathrm{m})$. (D, H) Merge at high magnification (Bar: $100 \mu \mathrm{m})$. 


\section{Acknowledgements}

This paper is dedicated to the memory of A.R. Moossa, MD and Sun Lee, MD.

\section{References}

1 Goldblum JR: An approach to pleomorphic sarcomas: can we subclassify, and does it matter? Mod Pathol 27: S39-S46, 2014.

2 Agaimy A, Gaumann A, Schroeder J, Dietmaier W, Hartmann A, Hofstaedter F, Wünsch PH and Mentzel T: Primary and metastatic high-grade pleomorphic sarcoma/malignant fibrous histiocytoma of the gastrointestinal tract: an approach to the differential diagnosis in a series of five cases with emphasis on myofibroblastic differentiation. Virchows Arch 451: 949-957, 2007.

3 Taubes G: Play of light opens a new window into the body. Science 276: 1991-1993, 1997.

4 Neri D, Carnemolla B, Nissim A, Leprini A, Querzè G, Balza E, Pini A, Tarli L, Halin C, Neri P, Zardi L and Winter G: Targeting by affinity-matured recombinant antibody fragments of an angiogenesis associated fibronectin isoform. Nat Biotechnol 15: 1271-1275, 1997.

5 Chambers AF, MacDonald IC, Schmidt EE, Koop S, Morris VL, Khokha R and Groom AC: Steps in tumor metastasis: new concepts from intravital videomicroscopy. Cancer Metastasis Rev 14: 279-301, 1995.

6 Zhao M, Yang M, Li XM, Jiang P, Baranov E, Li S, Xu M, Penman S and Hoffman RM: Tumor-targeting bacterial therapy with amino acid auxotrophs of GFP-expressing Salmonella typhimurium. Proc Natl Acad Sci USA 102: 755-760, 2005.

7 Wang X, Fu X and Hoffman RM: A new patient-like metastatic model of human lung cancer constructed orthotopically with intact tissue via thoracotomy in immunodeficient mice. Int $\mathbf{J}$ Cancer 51: 992-995, 1992.

8 Yamamoto M, Zhao M, Hiroshima Y, Zhang Y, Shurell E, Eilber FC, Bouvet M, Noda M and Hoffman RM: Efficacy of tumortargeting salmonella A1-R on a melanoma patient-derived orthotopic xenograft (PDOX) nude-mouse model. PLoS One 11: e0160882, 2016.

9 Fu X, Guadagni F and Hoffman RM: A metastatic nude-mouse model of human pancreatic cancer constructed orthotopically with histologically intact patient specimens. Proc Natl Acad Sci USA 89: 5645-5649, 1992.

10 Hiroshima Y, Maawy AA, Katz MH, Fleming JB, Bouvet M, Endo I and Hoffman RM: Selective efficacy of zoledronic acid on metastasis in a patient-derived orthotopic xenograph (PDOX) nude-mouse model of human pancreatic cancer. J Surg Oncol 111: 311-315, 2015.

$11 \mathrm{Fu} \mathrm{X}$ and Hoffman RM: Human ovarian carcinoma metastatic models constructed in nude mice by orthotopic transplantation of histologically-intact patient specimens. Anticancer Res 13: 283-286, 1993.

12 Hiroshima Y, Zhang Y, Zhang N, Maawy A, Mii S, Yamamoto M, Uehara F, Miwa S, Yano S, Murakami T, Momiyama M, Chishima T, Tanaka K, Ichikawa Y, Bouvet M, Murata T, Endo I and Hoffman RM: Establishment of a patient-derived orthotopic Xenograft (PDOX) model of HER-2-positive cervical cancer expressing the clinical metastatic pattern. PLoS One 10: e0117417, 2015.
13 Murakami T, Kiyuna T, Kawaguchi K, Igarashi K, Singh AS, Hiroshima Y, Zhang Y, Zhao M, Miyake K, Nelson SD, Dry SM, Li Y, DeLong JC, Lwin TM, Chishima T, Tanaka K, Bouvet M, Endo I, Eilber FC and Hoffman RM: The irony of highlyeffective bacterial therapy of a patient-derived orthotopic xenograft (PDOX) model of Ewing's sarcoma, which was blocked by Ewing himself 80 years ago. Cell Cycle 16: 10461052, 2017.

14 Metildi CA, Kaushal S, Luiken GA, Talamini MA, Hoffman RM and Bouvet $\mathrm{M}$ : Fluorescently labeled chimeric anti-CEA antibody improves detection and resection of human colon cancer in a patient-derived orthotopic xenograft (PDOX) nude mouse model. J Surg Oncol 109: 451-458, 2014.

15 Furukawa T, Kubota T, Watanabe M, Kitajima M and Hoffman RM: Orthotopic transplantation of histologically intact clinical specimens of stomach cancer to nude mice: correlation of metastatic sites in mouse and individual patient donors. Int $\mathbf{J}$ Cancer 53: 608-612, 1993.

16 Kiyuna T, Murakami T, Tome Y, Igarashi K, Kawaguchi K, Russell T, Eckardt MA, Crompton J, Singh A, Bernthal N, Bukata S, Federman N, Kanaya F, Eilber FC and Hoffman RM: Labeling the stroma of a patient-derived orthotopic xenograft (PDOX) mouse model of undifferentiated pleomorphic soft-tissue sarcoma with red fluorescent protein for rapid non-invasive imaging for drug screening. J Cell Biochem 118: 361-365, 2017.

17 Kiyuna T, Murakami T, Tome Y, Kawaguchi K, Igarashi K, Zhang Y, Zhao M, Li Y, Bouvet M, Kanaya F, Singh A, Dry S, Eilber FC and Hoffman RM: High efficacy of tumor-targeting Salmonella typhimurium A1-R on a doxorubicin- and dactolisibresistant follicular dendritic-cell sarcoma in a patient-derived orthotopic xenograft PDOX nude mouse model. Oncotarget 7: 33046-33054, 2016.

18 Hoffman RM and Yang M: Subcellular imaging in the live mouse. Nat Protoc 1: 775-782, 2006.

19 Hoffman RM and Yang M: Color-coded fluorescence imaging of tumor-host interactions. Nat Protoc 1: 928-935, 2006.

20 Suetsugu A, Katz M, Fleming J, Truty M, Thomas R, Saji S, Moriwaki $\mathrm{H}$, Bouvet $\mathrm{M}$ and Hoffman RM: Imageable fluorescent metastasis resulting in transgenic GFP mice orthotopically implanted with human-patient primary pancreatic cancer specimens. Anticancer Res 32: 1175-1180, 2012.

21 Kiyuna T, Murakami T, Tome Y, Kawaguchi K, Igarashi K, Miyake K, Kanaya F, Singh A, Eilber FC and Hoffman RM: Analysis of stroma labeling during multiple passage of a sarcoma imageable patient-derived orthotopic xenograft (iPDOX) in eed fluorescent protein transgenic nude mice. J Cell Biochem 118: 3367-3371, 2017.

22 Yang M, Reynoso J, Bouvet M and Hoffman RM: A transgenic red fluorescent protein-expressing nude mouse for color-coded imaging of the tumor microenvironment. J Cell Biochem 106: 279-284, 2009.

23 Kawaguchi K, Igarashi K, Miyake K, Kiyuna T, Miyake M, Singh AS, Chmielowski B, Nelson SD, Russell TA, Dry SM, Li Y, Unno M, Singh SR, Eilber FC and Hoffman RM: Patterns of sensitivity to a panel of drugs are highly individualised for undifferentiated/unclassified soft tissue sarcoma (USTS) in patient-derived orthotopic xenograft (PDOX) nude-mouse models. J Drug Target 2018: 1-6, 2018.

24 Igarashi K, Kawaguchi K, Kiyuna T, Miyake K, Miyake M, Singh AS, Eckardt MA, Nelson SD, Russell TA, Dry SM, Li Y, 
Yamamoto N, Hayashi K, Kimura H, Miwa S, Tsuchiya H, Singh SR, Eilber FC and Hoffman RM: Tumor-targeting Salmonella typhimurium A1-R is a highly effective general therapeutic for undifferentiated soft tissue sarcoma patientderived orthotopic xenograft nude-mouse models. Biochem Biophys Res Commun 497: 1055-1061, 2018.

25 Kawaguchi K, Igarashi K, Kiyuna T, Miyake K, Miyake M, Murakami T, Chmielowski B, Nelson SD, Russell TA, Dry SM, Li Y, Singh AS, Unno M, Eilber FC and Hoffman RM: Individualized doxorubicin sensitivity testing of undifferentiated soft tissue sarcoma (USTS) in a patient-derived orthotopic xenograft (PDOX) model demonstrates large differences between patients. Cell Cycle 17: 627-633, 2018.

26 Igarashi K, Kawaguchi K, Murakami T, Kiyuna T, Miyake K, Yamamoto N, Hayashi K, Kimura H, Nelson SD, Dry SM, Li Y, Singh AS, Miwa S, Odani A, Eilber FC, Tsuchiya $\mathrm{H}$ and Hoffman RM: A novel anionic-phosphate-platinum complex effectively targets an undifferentiated pleomorphic sarcoma better than cisplatinum and doxorubicin in a patient-derived orthotopic xenograft (PDOX). Oncotarget 8: 63353-66659, 2017.

27 Bouvet M, Tsuji K, Yang M, Jiang P, Moossa AR and Hoffman $\mathrm{RM}$ : In vivo color-coded imaging of the interaction of colon cancer cells and splenocytes in the formation of liver metastases Cancer Res 66: 11293-11297, 2006.
28 Mezawa $\mathrm{Y}$ and Orimo A: The roles of tumor- and metastasispromoting carcinoma-associated fibroblasts in human carcinomas. Cell Tissue Res 365: 675-689, 2016.

29 Graham N and Qian BZ: Mesenchymal stromal cells: emerging roles in bone metastasis. Int J Mol Sci 19: E1121, 2018.

30 Cortini M, Massa A, Avnet S, Bonuccelli G and Baldini N: Tumor-Activated mesenchymal stromal cells promote osteosarcoma stemness and migratory potential via IL-6 secretion. PLoS One 11: e0166500, 2016.

31 Tome Y, Kiyuna T, Uehara F, Bouvet M, Tsuchiya H, Kanaya F and Hoffman RM: Imaging the interaction of alphav integrinGFP in osteosarcoma cells with RFP-expressing host stromal cells and tumor-s caffold collagen in the primary and metastatic tumor microenvironment. J Cell Biochem 120: 283-289, 2019.

Received November 26, 2018

Revised November 30, 2018

Accepted December 3, 2018 